\title{
A new fast heat treatment process for cast A 356 alloy motorcycle wheel hubs
}

\author{
Shi-ping Lu', *Rui Du², Jian-ping Liu', Lin-can Chen', Shu-sen Wu' \\ 1. Zhejiang Wanfeng Motorcycle Wheel Co. Ltd, Xinchang 312500, Zhejiang, China \\ 2. State Key Lab of Materials Processing and Die \&Mould Technology, Huazhong University of Science and Technology, Wuhan 430074, China
}

\begin{abstract}
The normal T6 heat treatment process for cast A356 alloy generally requires about $15 \mathrm{~h}$. This longperiod procedure increases greatly the manufacturing cost and decreases the productivity in practical production. In this study, a new short-time heat treatment process with only $30 \mathrm{~min}$ solution time at $540{ }^{\circ} \mathrm{C}$ was developed for the production of motorcycle wheel hubs in order to reduce heat treatment time. Comparisons on microstructure evaluation and mechanical properties, such as tensile strength and ductility, were made between this new fast process and the conventional T6 heat treatment. The results revealed that this new heat treatment process enabled the spheroidization of the eutectic silicon thoroughly, while minimizing the growth of eutectic silicon. The A356 alloy after this new short-time heat treatment shows nearly equal mechanical properties compared with the same alloy heat treated in a normal T6 heat treatment. This investigation makes it possible to significantly improve the efficiency of heat treatment on A356 alloy and, at the same time, improve the mechanical properties of the alloy.
\end{abstract}

Key words: A356 alloy; short-time heat treatment; microstructure evaluation; mechanical properties
CLC numbers: TG146.21
Document code: $\mathrm{A}$
Article ID: 1672-6421(201801-011-06

\begin{abstract}
A 356 cast alloy has been widely used in automotive and aircraft industries owing to its outstanding properties, such as good castability, low density, high corrosion resistance and good weldability ${ }^{[1-2]}$. Moreover, A356 aluminum alloy has often been used as the material for motorbike wheel hubs ${ }^{[3]}$. With the requirement for larger delivery capacity, wheel hubs for motorcycles are becoming wider with more complex shapes. As an important part of the motorbike, strict quality rules for the mechanical properties of the wheel hub have been issued to ensure the security of the vehicles. However, as a typical hypoeutectic Al-Si alloy, the as-cast A356 alloy consists of coarse primary $\alpha$-Al dendrites and needle-shape eutectic silicon, which lowers severely the alloy's mechanical properties ${ }^{[4]}$. It is known that the mechanical properties are determined by controlling the microstructures of the alloys. Heat treatment is a common means for the spheroidization of the eutectic silicon ${ }^{[5,6]}$. Therefore, it is vital to control the microstructures of A356 alloy through heat treatment to improve the mechanical properties of the castings.
\end{abstract}

\section{*Rui Du}

Male, born in 1993, Ph. D candidate. His research interests mainly focus on the light-weight materials, and metal matrix composites.

E-mail: ruidu@hust.edu.cn

Received: 2017-04-21; Accepted: 2017-12-26
Conventional T6 heat treatment, which includes a solution treatment process followed by rapid quenching and an aging process, has been well understood. During this procedure, alloying elements are dissolved into $\alpha-\mathrm{Al}$ crystals to form the supersaturated solid solution. After that, intermetallics precipitate from the matrix in the form of $\beta$ ", $\beta$ ' or $\beta$ among the annealing process, decided by aging time and temperature ${ }^{[7]}$. As for A356 alloy, belonging to the Al-Si-Mg ternary alloy system, precipitation strengthening may mainly attribute to $\mathrm{Mg}_{2} \mathrm{Si}$ (i.e., $\beta$ phase) precipitation ${ }^{[8]}$.

Zhang et al ${ }^{[9]}$ reported that $\mathrm{Mg}_{2} \mathrm{Si}$ phase in A356 would be dissolved completely at $540{ }^{\circ} \mathrm{C}$ in only half an hour, but the spheroidization of eutectic silicon and homogenization of $\alpha$-Al dendrites generally need a longer time. In order to improve the alloy's strength and ductility, the parameters of heat treatment carried out in industry are those developed by ASTM B917 standards: solution heat treatment at a temperature of $540{ }^{\circ} \mathrm{C}$ for $8 \mathrm{~h}$ to $12 \mathrm{~h}$, and then articficial aging at $170{ }^{\circ} \mathrm{C}$ for $3-5$ hours ${ }^{[10]}$. Although the existing $\mathrm{T} 6$ treatment with a long period of time is greatly beneficial to the spheroidization of eutectic silicon, the long T6 heat treatment cycle greatly increases the manufacturing cost and decreases the productivity. Nevertheless, several researchers have already taken issue with the necessity of long-time heat treatment. Shivkumar ${ }^{[11]}$ found that for A356 alloy, a solution heat treatment of only $50 \mathrm{~min}$ at $540{ }^{\circ} \mathrm{C}$ was 
sufficient to obtain a homogeneous distribution of $\mathrm{Si}$ and $\mathrm{Mg}$ in $\alpha$-Al matrix. Yang C L, et al. ${ }^{[12]}$ found the solution time could be reduced to about $30 \mathrm{~min}$. In general, the eutectic Si will undergo three successive steps during heat treatment: disintegration, spheroidization and coarsening ${ }^{[13]}$. Ogris et al. ${ }^{[14]}$ has made a theoretical model to describe the spheroidization of eutectic $\mathrm{Si}$ and calculated the time of this process. His research indicated the spheroidization of eutectic Si took place within about 5 min after the beginning of heat treatment, and the saturated and homogeneous solid solution alloy could be obtained after only $30 \mathrm{~min}$ at $540{ }^{\circ} \mathrm{C}$. Obviously, there are two opposite views about the time of solution heat treatment: one thinks that a long period time of solution heat treatment is essential, the other believes that the time of solution heat treatment can be greatly reduced.

However, these studies ${ }^{[11-14]}$ concerning short-term heat treatment mainly focus on the evaluation of the microstructure, but ignore the relationship between the microstructure and mechanical properties, especially the influence on tensile strength and ductility. Furthermore, the different results between two kinds of heat treatment and the reasons for these results require further investigation. In this study, the authors want to reveal the mechanism of the fast heat treatment with a short-term solution heat treatment of about $30 \mathrm{~min}$, and make comparisons on microstructure evaluation and mechanical properties such as tensile strength and ductility between this new process and conventional $\mathrm{T} 6$ treatment.

\section{Experimental procedures}

Commercial A356 alloy with a nominal composition of A1$7.2 \% \mathrm{Si}-0.4 \% \mathrm{Mg}-0.15 \% \mathrm{Ti}-0.12 \% \mathrm{Fe}$ (mass fraction) was melted in a gas furnace. The melt was held at $750{ }^{\circ} \mathrm{C}$, and then degassed with pure nitrogen gas for $15 \mathrm{~min}$. Then, $0.015 \% \mathrm{Sr}$ was added in $\mathrm{Al}-10 \% \mathrm{Sr}$ master alloy into the melt to modify the eutectic Si. After that, the melt was held at $720{ }^{\circ} \mathrm{C}$ for 15 min to homogenize temperature, and then poured into the pre-heated permanent mould to get castings. A typical special-wide wheel hub product with a diameter of $490 \mathrm{~mm}$ and width of $110 \mathrm{~mm}$ is shown in Fig. 1. After casting, specimens were cut from the rim of the wheel hubs. Half of the specimens were heat treated according to ASTM standard B917-01 at a solution temperature of $540^{\circ} \mathrm{C}$ for $10 \mathrm{~h}$ and followed by an aging of $5 \mathrm{~h}$ at $170{ }^{\circ} \mathrm{C}$. The other half were heat treated with the new fast process: solution treated at $540{ }^{\circ} \mathrm{C}$ for 30 min followed by quenching immediately in $70^{\circ} \mathrm{C}$ water, and then artificial aging at $180^{\circ} \mathrm{C}$ for $90 \mathrm{~min}$ followed by air cooling.

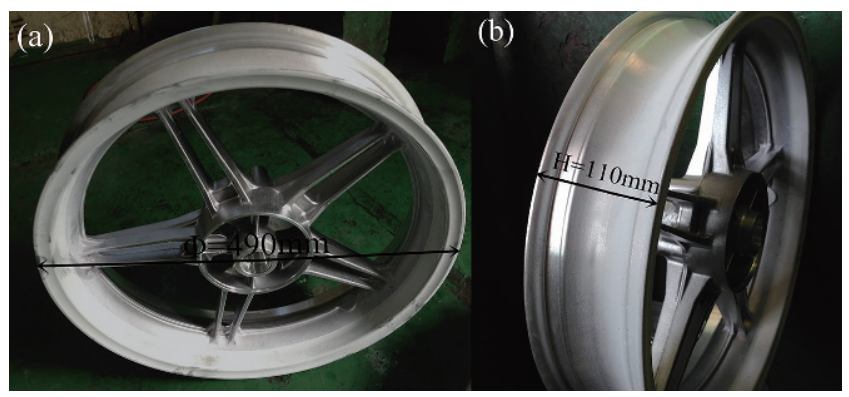

Fig. 1: Photos of a wheel hub: (a) front view; (b) side view
The chemical composition of the casting was determined by an Optical Emission Spectrometer (SHIMADZU PDA7000) and final results indicated that its composition fit well with nominal compositions. All tests were repeated 5 times in both as-cast and the above two different heat treatment conditions. The metallographic samples were etched with diluted hydrofluoric acid for $15 \mathrm{~s}$ after polishing to reveal the microstructure morphologies. A SHIMADZU XRD-7000S $\mathrm{X}$-ray diffractometer with $\mathrm{Cu} \mathrm{Ka}$ radiation operated at $40 \mathrm{kV}$ and $40 \mathrm{~mA}$ was used to identify the phases in the alloys. Optical microscopy and scanning electron microscopy (FEI Nova450) with an energy dispersive X-ray analysis were employed to examine the microstructures of the alloys. A transmission electron microscope (FEI Tecnai-G2) was introduced for TEM observation and identification of precipitates in the aging process. TEM thin foils were prepared using both mechanical technology and ion beam thinning.

The following parameters of mean diameter and roundness were introduced to measure the characteristics of eutectic $\mathrm{Si}$ in samples from more than 20 microstructure photos with different fields by Image ProPlus Software. The above parameters were defined as follows ${ }^{[8]}$.

Mean Diameter $(M D): M D=\frac{\sum_{i}^{n} D_{i}}{n}$

where $D_{i}$ is the length of transversal lines passing through eutectic silicon's centroid, and every length of $D_{i}$ measured at $2^{\circ}$ intervals, $n$ is the total number of transversal lines.

Roundness $(R): R=\frac{p^{2}}{4 \pi S}$

where $p$ and $S$ represent the perimeter and area of a eutectic silicon, respectively. $R=1$ if the shape is a circle, while $R>1$ means that it deviates from a circle's shape.

Room temperature tensile tests for the sample were performed on a SHIMADZU AG-100KN tester with a $1 \mathrm{~mm} \cdot \mathrm{min}^{-1}$ crosshead speed. Herein, tensile data were taken from the average value of 10 specimens.

\section{Results and discussion}

\subsection{Differences of microstructure evaluation in two kinds of heat treatmented samples}

The X-ray diffraction results of A356 with and without heat treatment are shown in Fig. 2. First of all, in order to identify intermetallics with a low content in the alloy, the scanning speed of X-ray diffractometer of $1^{\circ} \cdot \mathrm{min}^{-1}$ was used, which is the lowlimit speed of the chosen instrument. All samples are composed of $\alpha-\mathrm{Al}$ phase and Si phase without any slight difference, which means that whether with heat treatment or not, other obvious phases were not found in A356 alloys. Furthermore, Mgcontaining and $\mathrm{Fe}$-containing intermetallics were not traced by X-ray diffraction even though fine X-ray detection was applied. On the one hand, it may be due to the trace content of intermetallics such as $\mathrm{Mg}_{2} \mathrm{Si}$ and $\mathrm{Al}_{9} \mathrm{Fe}_{2} \mathrm{Si}_{2}$. On the other hand, it also indicates that factory-produced A356 alloy is quite pure. 


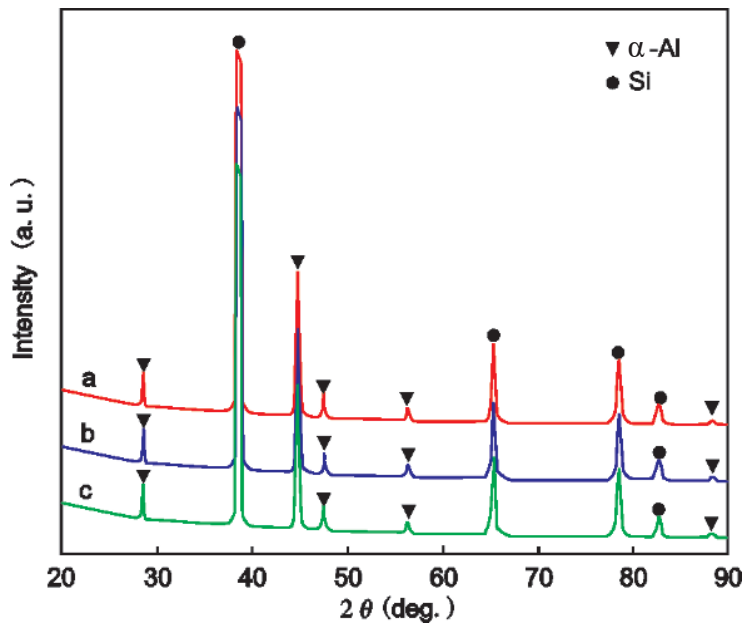

Fig. 2: Low speed scanning XRD patterns of A356 alloys: (a) as-cast A356 sample; (b) normal T6 heat treated sample; (c) fast heat treated sample


Fig. 3: Optical microstructures of as-cast A356: (a) low magnification; (b) high magnification
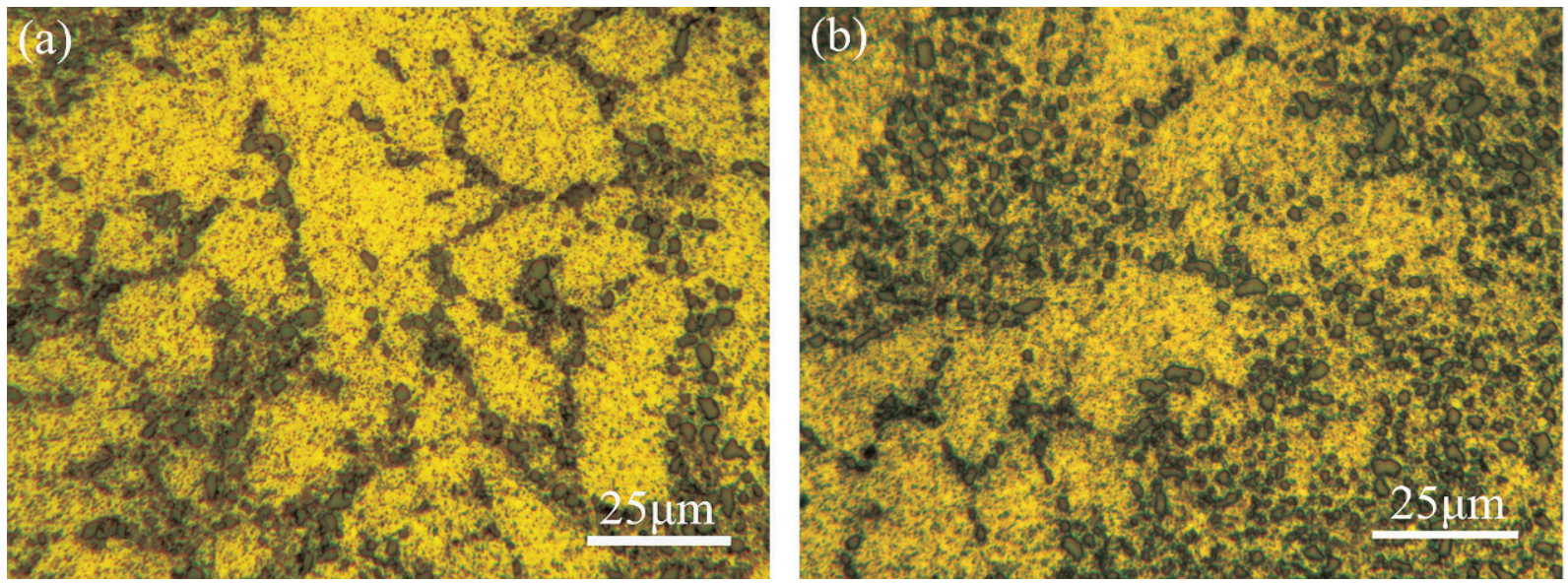

Fig. 4: Optical microstructures of A356 after different heat treatments: (a) normal T6; (b) fast heat treatment

However, after careful comparison, some differences are still found between the two kinds of heat treatments from optical microstructure observation. Though the average size of their eutectic Si are all reduced and get spheroidized during heat treatment, the mean length of Si phases in normal heat treatment is a little bit larger than that in the fast treatment, and Si phases in normal heat treatment also exhibits rounder shape compared
The typical optical microstructures of as-cast A356 samples are shown in Fig. 3, in which the dendrite phase is $\alpha$-Al phase and the rod-like phase is eutectic silicon. It can be found that the $\alpha-\mathrm{Al}$ phase and eutectic silicon are quite coarse with inhomogeneous morphology, and Fig. 3(b) shows eutectic silicon in as-cast state asgenerally acicular shape.

It is known that heat treatment leads to the spheroidization of eutectic Si and homogenization of $\alpha$-Al dendrites. Figure 4 shows the microstructure of the samples after different heat treatments. Figure 4(a) corresponds to the normal heat treatment and Fig. 4(b) corresponds to the fast method. Compared with the as-cast microstructure in Fig. 3, most of the eutectic Si phases became round and smooth, and their mean length also decreased obviously. Furthermore, not only was the distribution of the silicon phase improved greatly, but also the $\alpha$-Al dendrites became rounder and more uniform. 

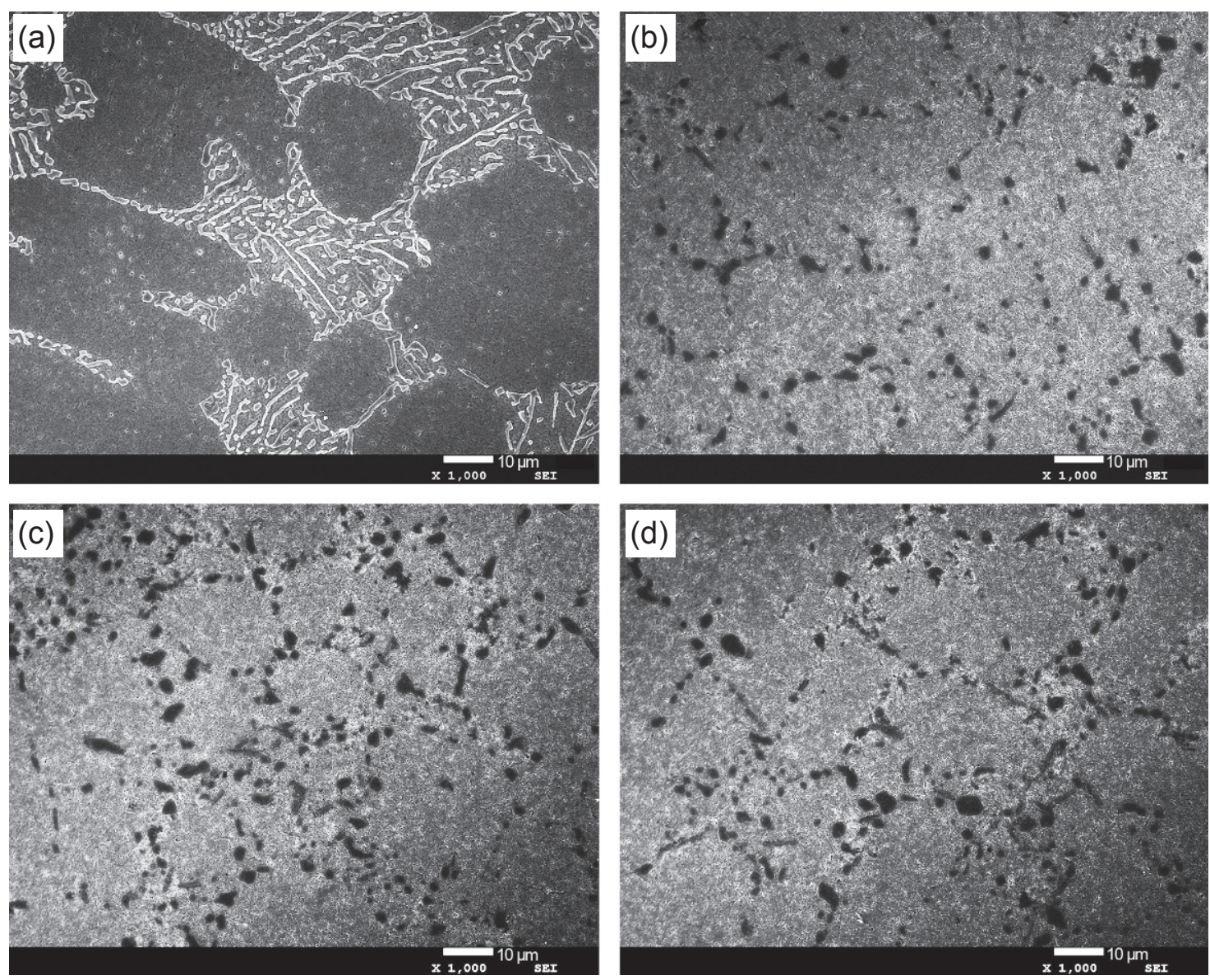

Fig. 5: SEM image of A356 alloys in different stages: (a) as-cast condition; (b) quenching after $\mathbf{3 0}$ min solution treatment; (c) after fast T6 heat treatment; (d) after normal T6 heat treatment

entire heat treatment and their size increases significantly, which can be found in Fig. 5(b), (c) and (d).

Figure 6 summarizes the average values of mean diameter and roundness of eutectic Si particles in the as-cast state and two kinds of heat treatments. The average value of the mean diameter of the eutectic Si particles in the as-cast state is 4.53 $\mu \mathrm{m}$, in normal T6 state is $2.98 \mu \mathrm{m}$, and fast treatment's value is only $2.24 \mu \mathrm{m}$ [Fig. 6(a)]. It can be seen from Fig. 6(b) that the roundness $R$ of eutectic $\mathrm{Si}$ particles in the as-cast state is 3.78. This means that the morphology of eutectic Si particles is far from a circle's shape in the as-cast state. Nevertheless, the $R$ values in normal T6 heat treatment state and fast heat treatment state are both significantly reduced to only 1.23 and 1.81 , respectively, indicating that the spheroidization of eutectic silicon particles is quite obvious. These results match well with conclusions obtained from the observation of optical and SEM microstructures.

As suggested by other researchers, after $10 \mathrm{~min}$ of solution heat treatment at $540{ }^{\circ} \mathrm{C}, \mathrm{Mg}_{2} \mathrm{Si}$ began to dissolve in the $\alpha$-Al matrix and this process would soon complete ${ }^{[15]}$. However, some common Fe-containing intermetallic compounds such as $\beta-\mathrm{Al}_{9} \mathrm{Fe}_{2} \mathrm{Si}_{2}$ phase and $\pi-\mathrm{Al}_{8} \mathrm{Si}_{6} \mathrm{Mg}_{3} \mathrm{Fe}$ phase are quite difficult to


Fig. 6: Average values of mean diameter (a) and roundness (b) 
dissolve during solution heat treatment, and exist in $\alpha$-Al matrix with needle shape ${ }^{[16]}$. The $\mathrm{Mg}_{2} \mathrm{Si}$ dissolution is the main reason for later age hardening, in accordance with the research results of Polmear ${ }^{[17]}$. The existence of Fe-containing intermetallics not only reduces the content of $\mathrm{Mg}$ to dissolve into the $\alpha$-Al matrix, but also decreases the mechanical properties of the alloy because of their shape. Hence, it is important to restrict the content of Fe element in A356 alloy. However, in this research, Fe-containing intermetallic compounds were seldom observed in X-ray diffraction and SEM microstructures. Thus, the time of solution heat treatment can be shortened to nearly $30 \mathrm{~min}$.

Precipitation hardening of A356 alloys occur due to the formation of precipitates with $\mathrm{Mg}$ and $\mathrm{Si}$ elements which had

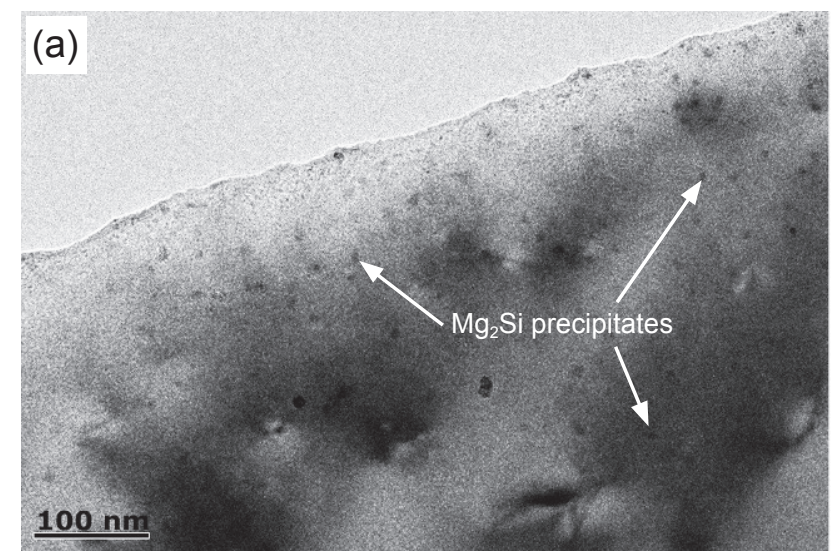

been dissolved into supersaturated solid solution in the solution treatment process. However, in this study, although the time of solution heat treatment has been shortened to $30 \mathrm{~min}$, the precipitation behavior of A356 alloy did not change. Figure 7(a) is the TEM image of $\mathrm{Mg}_{2} \mathrm{Si}$ precipitates in A356 alloy matrix after fast heat treatment. According to the previous results in references ${ }^{[18-19]}$, these disc-shaped precipitates are considered to be $\mathrm{Mg}_{2} \mathrm{Si}$ precipitates. It can be seen that the $\mathrm{Mg}_{2} \mathrm{Si}$ precipitates have near-spherical shape with a diameter of about $10 \mathrm{~nm}$. High dislocation densities adjacent $\mathrm{Mg}_{2} \mathrm{Si}$ precipitates are shown in Fig. 7(b). It is obvious to confirm that precipitation of $\mathrm{Mg}_{2} \mathrm{Si}$ still occurs in A356 alloys after processed by the new fast heat treatment.

Fig. 7: TEM of A356 alloy matrix after fast heat treatment: (a) $\mathrm{Mg}_{2} \mathrm{Si}$ precipitates; (b) dislocations adjacent to $\mathrm{Mg}_{2}$ Si precipitates

In conclusion, the change of eutectic Si takes place mainly in a short time. In practical production, a short-term solution heat treatment can make the silicon particles rounder and at the same time prohibit them from coarsening. Therefore, it is necessary and effective to reduce the solution heat treatment time.

\subsection{Effect of fast heat treatment on mechanical properties}

The mechanical properties of A356 alloy without and with different heat treatments were tested and their ultimate tensile strength (UTS) and elongation percentage (EL) were listed in Table 1. From Table 1, it can be seen that the mechanical properties are greatly improved by the heat treatment, especially the ultimate tensile strength. Compared with the UTS of A356 in as-cast condition, the ultimate tensile strengths of A356 after normal $\mathrm{T} 6$ heat treatment or fast heat treatment are improved by $29 \%$ and $31 \%$, respectively. In addition, the elongation

Table 1: Tensile properties of A356 alloys after different heat treatment

$\begin{array}{cccc}\text { Condition of samples } & \text { UTS (MPa) } & \text { EL(\%) } & \begin{array}{c}\text { Total time } \\ \text { of heat } \\ \text { treatment (h) }\end{array} \\ \text { As-cast } & 218 & 5.63 & 0 \\ \text { Fast heat treatment } & 286 & 6.90 & 2 \\ \text { Normal T6 heat treatment } & 282 & 7.55 & 15\end{array}$

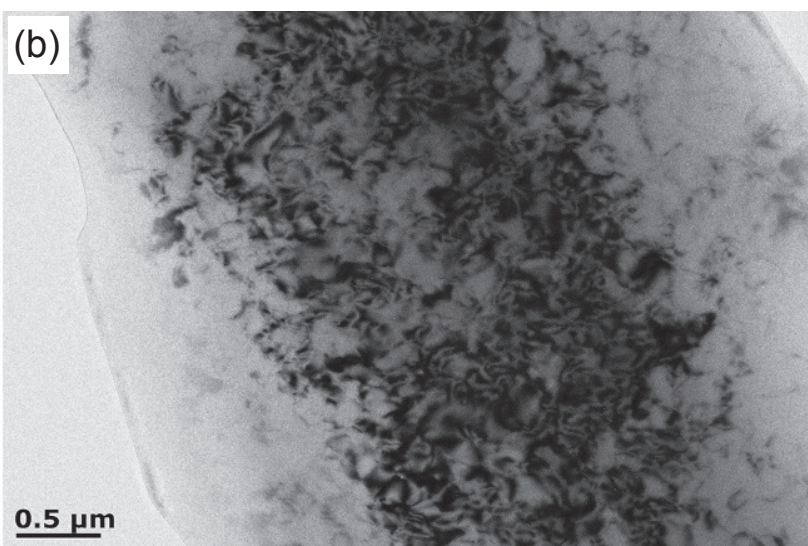

percentages after normal T6 heat treatment or fast heat treatment are also improved by $34 \%$ and $23 \%$, respectively.

Tensile results have revealed that the ultimate tensile strength and ductility of A356 alloy after heat treatment are enhanced significantly by the homogenization of $\alpha$-Al dendrites and improved equilibrium levels of eutectic Si by solution treatments. Since the eutectic Si particles have a tendency to fracture but not to deform under tensile stress because they possess high hardness and low ductility, the existence of brittle silicon particles in the matrix increases the trend of cracking. During solution heat treatment, the needle-shape eutectic silicon disintegrates to particle-like silicon, spheroidizes and then grows up, which will decrease the mean diameter and make the roundness approach to 1 . Near-spherical shaped and small eutectic Si particles inhibit crack nucleation and resist plastic deformation, which improves strength and ductility. Microstructure observation has also proved that the spheroidization of eutectic Si particles is obvious and the size of Si particles is also reduced obviously. In addition, the high dislocation densities adjacent $\mathrm{Mg}_{2} \mathrm{Si}$ precipitates can be clearly captured in Fig. 7(b). These dislocation lines tangle each other, and the dislocations also tangle around the precipitates, which produces a strengthening effect through dislocation pinning. The above results can be responsible for the increase of mechanical properties of the A356 alloy after heat treatment, especially good ductility. 
The eutectic Si particles still keep growing larger at a slow rate even though the majority of eutectic Si particles have been spheroidized. However, due to the eutectic Si particles possessing high hardness and low ductility, the larger the eutectic silicon particles, the lower the fracture stress of the A356 alloys. Then, the ultimate tensile strength decreases and ductility increases slightly. The results of UTS and elongation percentage of A356 alloys after different heat treatments in Table 1 have also proved this conclusion.

\section{Conclusions}

The influence of a new short-term heat treatment on the microstructures and mechanical properties for A356 casting alloys was studied and compared with the alloy with normal T6 heat treatment. Based on the observations, the main conclusions can be summarized as follows:

(1) A fast heat treatment process of A356 alloy has been developed for the production of motorcycle wheel hubs, in which the solution time is only $30 \mathrm{~min}$ and artificial aging time is about $90 \mathrm{~min}$. This new fast heat treatment on A356 alloys can shorten the solution heat treatment time because the spheroidization of eutectic silicon and the dissolution of $\mathrm{Mg}_{2} \mathrm{Si}$ phase could be finished in only $30 \mathrm{~min}$ at $540^{\circ} \mathrm{C}$.

(2) Fast heat treatment not only decreases the size of eutectic Si phase but also enhances greatly the spheroidization degree of eutectic Si particles, up to the level of normal T6 heat treatment.

(3) After fast heat treatment, the ultimate tensile strength and elongation percentage of A356 are improved 31\% and $23 \%$, respectively, compared with the as-cast alloys. Morever, compared with the same alloy heat treated in normal T6 heat treatment, A356 alloy after the new fast heat treatment shows nearly equal mechanical properties.

\section{References}

[1] Youn S W, Kang C G. Characterization of age-hardening behavior of eutectic region in squeeze-cast A356-T5 alloy using nanoindenter and atomic force microscope. Materials Science \& Engineering A, 2006, 425: 28-35.

[2] Zhang $L Y$, Jiang $Y H, M a ~ Z$, et al. Effect of cooling rate on solidified microstructure and mechanical properties of aluminum A356 alloy. Journal of Materials Processing Technology, 2008, 207: 107-111.

[3] Roy M J, Maijer D M, Dancoine L. Constitutive behavior of as-cast A356. Materials Science \& Engineering A, 2012, 548: 195-205.
[4] Boschetto A, Costanza G, Quadrini F, et al. Cooling rate inference in aluminum alloy squeeze casting. Materials Letters, 2007, 61: 2969-2972.

[5] Qayyum M S. Production of a Permanent Mold Gravity Die Cast A356.0 Aluminum Alloy Motorbike Shock Absorber through Casting Simulation. Key Engineering Materials, 2015, 659: 676680.

[6] Makhlouf M M, Guthy H V. The aluminum-silicon eutectic reaction: mechanisms and crystallography. Journal of Light Metals, 2001, 1: 199-218.

[7] Myhr O R, et al. Modeling of the microstructure and strength evolution in Al-Mg-Si alloys during multistage thermal processing. ActaMaterialia, 2004, 52: 4997-5008.

[8] Zhu M, Jian Z, Yang G, et al. Effects of T6 heat treatment on the microstructure, tensile properties, and fracture behavior of the modified A356 alloys. Materials \& Design, 2012, 36: 243-249.

[9] Zhang D L, Zheng L H, St John D H. Effect of a short solution treatment time on microstructure and mechanical properties of modified Al-7wt\%Si-0.3wt.\%Mg alloy. Journal of Light Metals, 2002, 2: 27-36.

[10] Menargues S, Martín E, Baile M T, et al. New short T6 heat treatments for aluminum silicon alloys obtained by semisolid forming. Materials Science \& Engineering A, 2015, 621: 236242.

[11] Shivkumar S, Wang L, Keller C. Impact properties of A356-T6 alloys. Journal of Materials Engineering and Performance, 1994, 3: 83-90.

[12] Yang C L, Li Y B, Dang B, et al. Effects of cooling rate on solution heat treatment of as-cast A356 alloy. Transactions of Nonferrous Metals Society of China, 2015, 25: 3189-3196.

[13] Zhang Z, Tezuka H, and Kobayashi E. Effects of the Mn/Fe Ratio and Cooling Rate on the Modification of Fe Intermetallic Compounds in Cast A356 Based Alloy with Different Fe Contents. Materials Transactions, 2013, 54: 1484-1490.

[14] Ogris E, Wahlen A, Lüchinger $\mathrm{H}$, et al. On the silicon spheroidization in Al-Si alloys. Journal of Light Metals, 2002, 2: 263-269.

[15] Andersen S J, Marioara C D, Vissers R, et al. The structural relation between precipitates in Al-Mg-Si alloys, the Al-matrix and diamond silicon, with emphasis on the trigonal phase $\mathrm{U} 1-\mathrm{MgAl}_{2} \mathrm{Si}_{2}$. Materials Science \& Engineering A, 2007, 444: 157-169.

[16] Taylor J A, Schaffer G B, St John D H. The role of iron in the formation of porosity in Al-Si-Cu-based casting alloys: Part II. A phase-diagram approach. Metallurgical and Materials Transactions A, 1999, 30: 1651-1655.

[17] Polmear L J. Light alloys: metallurgy of the light metals. John Wiley \& Sons Press, 1995

[18] Vissers R, Huis M A V, Jansen J, et al. The crystal structure of the $\beta^{\prime}$ phase in Al-Mg-Si alloys. Acta Materialia, 2007, 55: 3815-3823.

[19] Andersen S J, Zandbergen H W, Jansen J, et al. The crystal structure of the $\beta^{\prime \prime}$ phase in Al-Mg-Si alloys. Acta Materialia, 2007, 46: 3283-3298. 